Jiaxiang $\mathrm{HAN}^{1, \mathrm{a}^{*}}$, Ying $\mathrm{CHEN}^{1, \mathrm{~b}^{*}}$ and Huijie $\mathrm{SUN}^{2 \mathrm{c}}$

\title{
FOREIGN DIRECT INVESTMENT SPILLOVER EFFECT ON CHINA'S SUSTAINABLE DEVELOPMENT
}

\begin{abstract}
The unbalanced growth of FDI in China has seriously affected the coordinated development of China's regional economies. Therefore, to achieve comprehensive, coordinated and sustainable development, China's main strategic task is determining how to adopt positive and effective FDI policies to reduce this regional imbalance in FDI. The purpose of this paper is to explore and study the spillover effects of foreign direct investment (FDI) on China's sustainable development. In this paper, based on the new political economics theory and overflow effects, comparative research and statistical research methods are adopted that combine static and dynamic analysis. Empirical research methods are combined with normative research to analyse the spillover effects of FDI on China's sustainable development, particularly under the new situation of global crisis and the accompanying difficulties, to determine how to promote China's FDI and the development of China's sustainable progress strategy. The study found that in 2018, FDI in China reached a value of 13.466 billion US \$, and the year-on-year growth in FDI in recent years has been basically stable at approximately $4 \%$. Asia is the main source of FDI in China. In 2018, the amount of FDI in Asia reached \$109.1938.7 billion, accounting for $83.33 \%$ of the total investment. Hong Kong, with its unique advantages, accounted for $72.12 \%$ of FDI in China. FDI inflows are mainly directed to primary industry and the service sector, and the growth rate of foreign investment in 2016 in these sectors was 68.52 and $170.77 \%$, respectively, compared with 2007. FDI also mainly flows to the eastern region of China. By the end of 2018, the amount of foreign capital utilized in the eastern region reached $\$ 1,622.9$ billion, representing $85.4 \%$ of the aggregate FDI in China. The effect of FDI on China mainly focuses on three areas: economic growth, social development and environmental protection. FDI has brought positive spillover effects to China's sustainable evolution, but with China's continuous development, especially the change in its economic development mode, it has been consistently exposed to negative spillover effects.
\end{abstract}

Keywords: FDI, sustainable development, spillover effect, new economic theory

\section{Introduction}

As socialism in China enters a new era, China's economy has changed from the pursuit of quantity to the pursuit of quality. After 70 years of continuous development, thanks to the hard work of the entire Chinese people, China has become the world's second largest economy and one of the world's largest countries with the greatest development potential.

During the rapid development of the 1970s, China constantly introduced foreign capital to engage in socialist construction. In current context, China is constantly introducing technology, talent and management experience to accelerate the upgrade of its industrial engineering structure and transform the pattern of economic development; the

\footnotetext{
${ }^{1}$ School of Geography and Tourism, Shaanxi Normal University, Xi'an 710119, Shaanxi, China, email: ashjx1022@snnu.edu.cn

${ }^{2}$ Zhengzhou Shengda University of Economics, Business \& Management, Zhengzhou 451191, Henan, China,

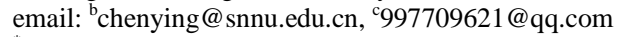

*Corresponding Author: chenying@snnu.edu.cn
} 
introduction of Foreign Direct Investment (FDI) in China has allowed it to proudly achieve numerous goals. FDI has contributed to the evolution of China. In terms of funding, FDI provides a large amount of capital for China's economic development; the amount may be insignificant compared with China's total domestic capital, but it can represent a meaningful investment in a specific industry. In terms of technology, China has introduced a large number of preferential policies for the introduction of advanced technologies. China has realized the transformation from "importing" to "going out" and is now committed to upgrading from "Made in China" to "Created in China". As far as employment is concerned, FDI directly or indirectly creates numerous jobs and alleviates the pressure of employment competition in China.

The International Union for Conservation of Nature (IUCN), United Nations Environment Programme (UNEP) and World Wide Fund for Nature or World Wildlife Fund (WWF) jointly published the World Outline for the Conservation of Nature, which defined the concept of "sustainable development", and China has established sustainable development as its basic strategy for national development [1]. In this new situation, General Secretary Xi Jinping, standing at the strategic height of history and of the current situation, proposed the "five-in-one" design [2]. Thus, sustainable development occupies a significant location in China's development process, and FDI has become a major factor affecting China's sustainable development. The impact of FDI on China mainly focuses on economic gain, social development and environmental protection [3]. Shahbnzi believes that China is currently in the three-phase superimposition period, and industrial organization transformation and upgrading have insufficient power. FDI provides financial support, but the location of FDI is in the more developed regions in China, which is important for China's sustainable development but less likely to provide effective support. Zang conducted a statistical investigation relating manufacturing data to FDI in recent years and confirmed that FDI is concentrated in labour-intensive and capital-intensive industries, where its ability to assist in the optimization of industrial structure has been challenged [4]. Lu analysed the mechanism of FDI's effect on the upgrading of industrial structure, taking the differences in regional financial markets as the starting point to explore whether there are differences in the impact of FDI on industrial structure upgrading in different financial markets [5]. These studies have a certain reference value, but their sample size is insufficient, and they have too many experimental design variables, which makes them difficult to replicate in practice.

This article analyses the mechanism through which FDI spillover affects China's sustainable development from a new perspective and then deeply analyses the impact of FDI spillover effects on China's sustainable development. Panel data models are used to study the impact of FDI on the unbalanced development of China's regional economy and the impact of China's regional economic growth on the regional distribution of FDI. Comparative and statistical research, static and dynamic analysis, and empirical and normative methods are used to conduct the analysis. This article will comprehensively review and organize previous research results on FDI, sustainable development and spillover effects in China and abroad and summarize the relevant data to lay a theoretical foundation for this research. This work will then focus on the spillover effect of FDI on China's sustainable development [6]. Combining the findings with typical cases, practical opinions and suggestions for China's FDI and sustainable development are offered that have certain practical significance and reference value. 


\section{Current research on the overflow effects of FDI on China's sustainable progress}

\section{FDI and sustainable progress}

(1) FDI and economic control

The global economic landscape is changing, and countries worldwide are paying increasing attention to the importance and necessity of sustainable development, especially developing countries such as China [7,8]. The increase in China's FDI, along with China's own development, has allowed China to gradually and slowly establish a perfect FDI control system involving all walks of life. FDI has played an indispensable role in the development of China. However, everything should be viewed critically. For the sustainable development of China, FDI has achieved some fruitful results, but there are also some problems. The first problem is the imbalance in regional and industrial development. Due to differences in the geographical environment, FDI is not evenly distributed in China. The eastern coastal areas have the most abundant FDI, while the western areas have the least; more FDI is directed to secondary industry, and less is invested in tertiary industry. Second, FDI is not beneficial to the endogenous growth of China's economy [9]. Although FDI brings funding and technology, which can help China's development for a period of time, it also squeezes the development space of local relevant industries, hindering or slowing down the long-term development of independent innovation ability and endogenous economic power. Finally, FDI still has some issues in its scale and structure, which need to be solved individually [10].

(2) FDI and social control

Social development includes many aspects of development, such as social structure, population, employment, education and health care [11]. The development of Chinese society through FDI is mainly divided into two effects: that on the labour market, including employment and labour protection, and that on the disparity between poor and rich and the resulting inequality. FDI produces a spillover effect on social control through its influence on the above two areas, including positive and negative aspects [12]. In terms of the impact of FDI on employment, although its contribution to employment in China has declined with the transformation of China's pattern of economic progress, it still plays a crucial role in some industries. In terms of the impact of FDI on labour protection, it brings advanced management experience in addition to capital and technology, which helps China to improve its labour protection system to better protect the rights and benefits of labour.

(3) FDI and environmental control

At different stages of development, each country must have different priorities. Since the reform and opening-up, China has emphasized financial development, with economic construction as the main focus. After the 19th National Congress, and even the 18th National Congress, of the CPC (Communist Party of China), China emphasized that "we want not only mountains of gold and silver but also clear water and green mountains". Environmental problems are an important issue in sustainable development, and solutions to environmental problems are beneficial to the implementation of sustainable development [13]. FDI has a certain relationship with environmental problems that produces both positive and negative spillover domino effects. From the perspective of FDI, which is mainly in trade and pollution-intensive industries, the transformation of China's economic development pattern will expedite solutions to environmental problems. In terms of the 
regions where FDI enters, although many preferential incentive policies have been introduced in western China, the expected effect of attracting FDI has not been achieved $[14,15]$.

\section{Research on the overflow effect of FDI on China's persistent development}

The effect of FDI on China is twofold. First, the direct impact can be seen in the short term, such as the growth of the economy and the increase in employment, which are direct effects. The second is the impact on sustainable development. With the sustained increase in FDI in China, FDI will have a strong spillover effect on China's sustainable development. This spillover effect mainly affects the three areas mentioned above: the economy, society and the environment [16].

First, examining the spillover effect of FDI on economic growth, FDI has enriched China's capital sources, improved its independent innovation ability through the introduction and transfer of technology, and thereby improved the quality of products and increased the core competitiveness of products for export. In addition, FDI provides a wide variety of jobs, reducing China's unemployment rate and improving the labour skills of workers.

Second, the spillover effect of FDI on social development includes many aspects. In the job market, FDI can motivate workers to invest more in their own education and drive companies to train more employees. In terms of FDI and labour relations, even if FDI squeezes the development space of an industry, it also forces the industry to continuously transform and upgrade to achieve a win-win result.

Third, FDI is considered to have a spillover effect of environmental protection. With the continuous and increasingly powerful development of China, FDI is gradually shifting from secondary industry to tertiary industry. FDI has led secondary industry in China to develop efficiency and labour prices. More importantly, FDI has resulted in China paying increasing attention to the environment, introducing relevant environmental policies, motivating the investing companies to perform their corresponding environmental obligations, and assuming liability for the corresponding environmental impacts.

\section{Research scheme for the overflow effect of FDI on China's sustainable development}

\section{Research methods}

The purpose of this article is to study the spillover effects of FDI on China's sustainable development through the use of new political economic theories and theories related to spillover effects by examining the uneven regional distribution of FDI and the unbalanced economic development of China's three major regions. Mechanism and empirical analysis are conducted, the impact of FDI on China's economic growth is compared, theoretical and decision-making references are provided to promote the better use of FDI and rationally guide its flow, ultimately aiming to solve the crises and dilemmas brought about by the new global situation, and promote the development of FDI and of China's FDI and sustainable development strategy. This paper adopts comparative and statistical research methods, static and dynamic analysis, and empirical and normative research. Comparative and statistical research are combined to collect extensive research results on the spillover effects of FDI from developed and developing countries on China's 
sustainable development. Data are collected, classified and organized and used as the basis for conducting this comparative analysis. In addition to extensively consulting Chinese and foreign documents, we refer to the WTO and other websites to obtain detailed and sufficient statistical data to capture the latest trends in the spillover effects of FDI on China's sustainable development. This lays a foundation for both the theoretical and the empirical research in this article. To combine static analysis with dynamic considerations, this article uses the partial equilibrium analysis method under static conditions to analyse the spillover effect of FDI on China's sustainable development. Through the partial equilibrium under static analysis, we can clearly see that FDI mainly affects China's economic, social and environmental aspects, with different degrees of positive and negative spillover effects. This analysis process provides a sufficient theoretical basis for solving a series of FDI sustainability issues. In addition, through the analysis of historical data, this paper determines the mechanism for the spillover effect of FDI on China's sustainable development.

\section{Research ideas}

Countries worldwide are closely connected. No country or region can develop in isolation from external cooperation. The overflow effect of FDI on sustainable development is a topic that every country or region should explore and study. After determining the key problems to be solved in the study, this paper studies the overflow effect of FDI on China's sustainable development through collected data and typical cases. By means of the new political economy theory and the relevant theoretical knowledge and research on spillover effects, combined with typical cases, this paper proposes feasible opinions and suggestions for China's FDI and sustainable development, which has certain practical significance and reference value.

Because this article specifically addresses the overflow effects of FDI on China's sustainable development, the analysis of the literature is limited, so the author focuses on spillover effects using the new political economics theory and related theory and on problems related to system analysis, but challenges remain, especially in extending the problem, which need to be further perfected. In addition, many documents and statistical data on the overflow effect of FDI on China's sustainable development are available, but limited public data exists, which limits the acquisition and analysis of data in the empirical analysis and to some extent affects the accuracy of the research conclusions.

\section{Discussion of the overflow effects of FDI on China's sustainable development}

\section{Research on the overflow effects of FDI on China's economic gains}

(1) Analysis of the source structure of China's FDI

China's open and inclusive policies attract FDI. By the end of 2018, 180 countries or regions had conducted FDI activities in China, which indicates that China is among the countries with the greatest development potential and attraction for foreign investment. Although global transnational investment in recent years has been somewhat sluggish compared with previous years, and the growth in China's FDI has declined due to rising labour prices and slowing economic growth, overall, China's gross FDI has been growing steadily, and this rising trend will continue. The sources of China's FDI are highly uneven 
in terms of continental contribution. In 2018, Asia was the main investor for FDI in China; in 2018, FDI from Asian countries in China reached as high as \$ 109.19387 billion, accounting for as much as $83.33 \%$. Africa has the least FDI in China, as the investment amount is only $\$ 657.46$ million and accounts for only $0.5 \%$. In terms of the distribution of countries and regions, the distribution of FDI is also unbalanced. As shown in Figure 1, the top 10 countries or regions contributing FDI in China in 2018 were Hong Kong, Singapore, the Virgin Islands, South Korea, Japan, the United States, the Cayman Islands, the Netherlands, Taiwan and Germany. China's direct investment from the above ten countries or regions reached $91.97 \%$, and other countries or regions accounted for the other $8.03 \%$. Between the top 10 countries or regions with direct investment in China, Hong Kong, by virtue of its unique advantages, accounts for $72.12 \%$ of direct investment in China. From this perspective, although China's FDI comes from a wide range of sources, it mainly comes from Chinese people. Hong Kong, Taiwan and Singapore are the three most prominent countries and regions investing, while the investment amount and scale of developed countries and regions such as Europe and the United States are limited.

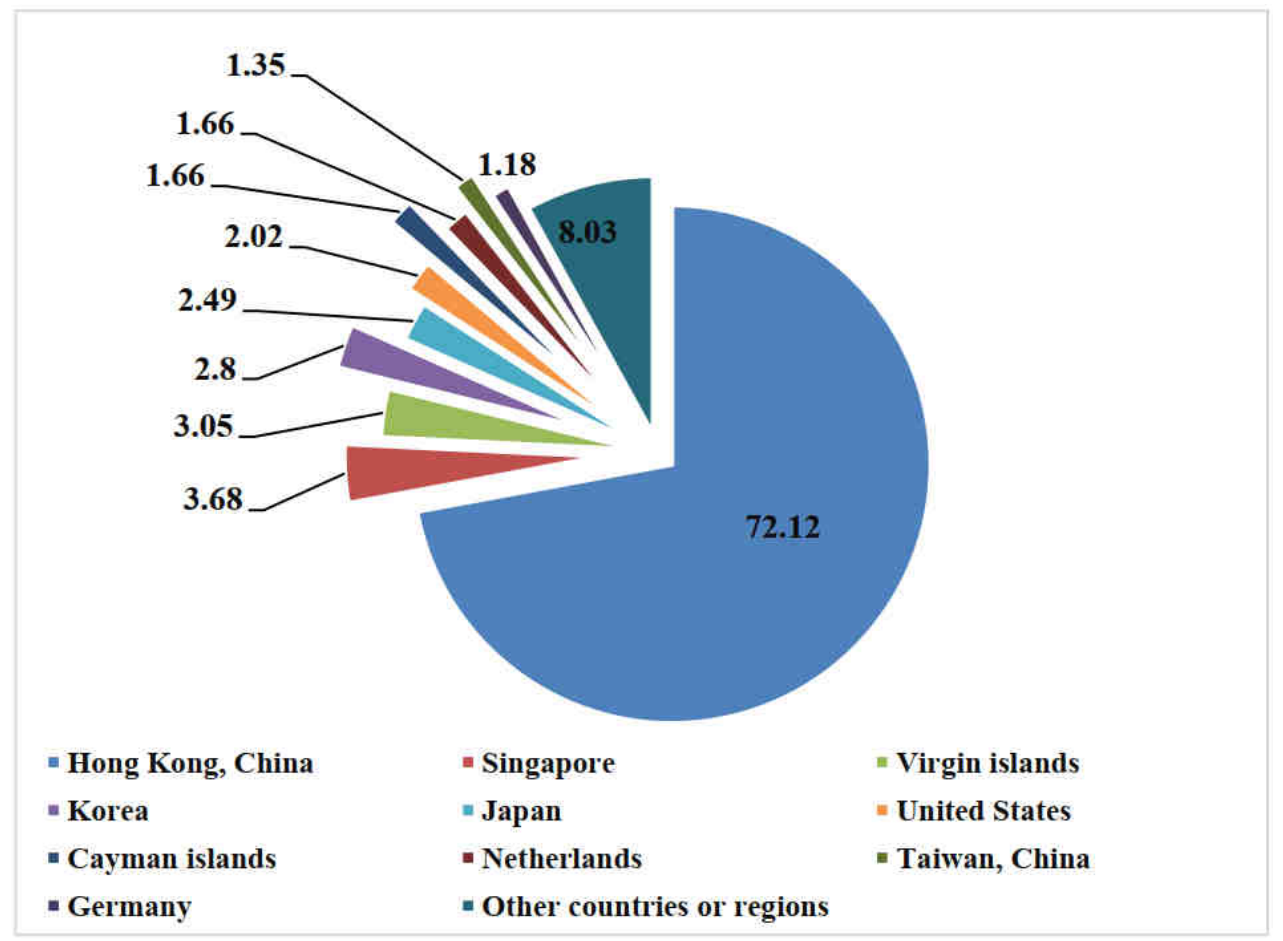

Fig. 1. Sector chart of the ratio of FDI sources in China in 2018

(2) Data on the amount of FDI in China from 2008 to 2018

With the extension of the reform and opening-up, China has attracted a large amount of FDI due to its preferential policies and cheap and abundant labour force. Since the starting point of the new century, FDI has been pouring into China, and the investment areas have been expanding from the southeast coastal areas to the northwest and northeast. 
The investment industry is gradually transforming from extensive industries such as manufacturing to sophisticated tertiary industries. In the new era, although China's economic development mode is undergoing transformation, and the demographic dividend is gradually disappearing, the stable investment environment, ideal infrastructure and substantial development potential still attract foreign investors to China. Driven by globalization, countries in worldwide are interconnected and interacting. China needs FDI, and whole world needs China, a dynamic and promising investment destination. Figure 2 is a statistical chart of the amount of FDI in China from 2008 to 2018. As shown, the total FDI in China in 2008 was 95.253 billion US dollars, while the total in 2018 reached as high as 134.966 billion US dollars, increasing by $41.69 \%$ in just ten years. It can be seen that an increasing number of countries, regions and enterprises are willing to invest in China, hoping to seize the opportunity presented by China's explosive growth and avoid being eliminated by missing the current trends [17]. In 2008 and 2010, the amount of FDI increased by 21.59 and $18.54 \%$ year on year, respectively, demonstrating rapid growth. Although the growth was slow or even declined from 2011 to 2014, this is normal. From 2015 to 2018, China's FDI rose 5.60, 4.1, 4.0 and 3.0 \%, respectively. Slow growth reflects the law of economic development, as although growth tends to slow, the amount of FDI on the whole remains large; as the world is experiencing increasingly close contact, and China's role in the international arena is growing, FDI in China will continue.

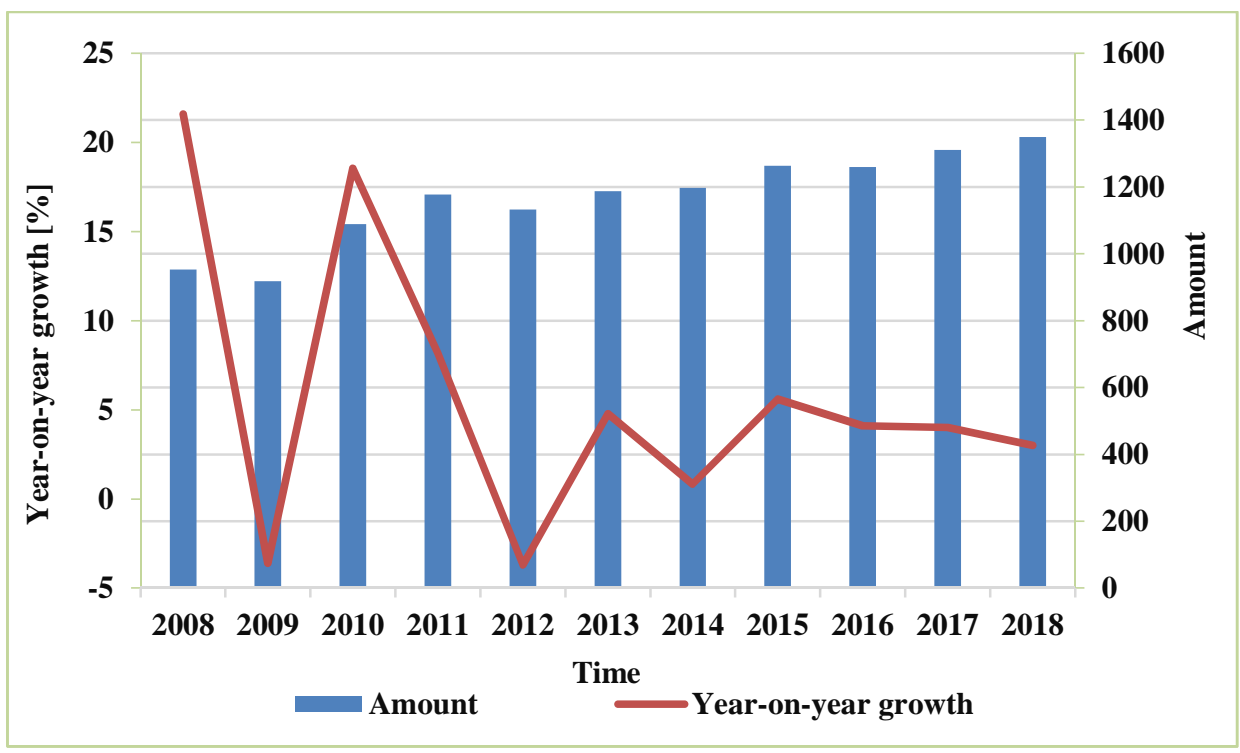

Fig. 2. Statistical figures for China's FDI from 2008 to 2018

\section{Research on the spillover effects of FDI on China's social progress}

(1) Geographical distribution of China's absorption of foreign investment

After nearly 40 years of development, although China has become the world's second largest country for attracting investment and has had world-renowned achievements in this regard, there are clear disparities in the geographical distribution of FDI [18]. Table 1 
shows the regional distribution of the absorption of foreign capital in China. At the end of 2018, the number of enterprises receiving FDI reached a total of 899,956 , but the distribution was uneven. Eastern enterprises receiving FDI numbered 757,828, for a proportion of $84.2 \%$, while enterprises in the midland and western areas numbered 90,763 and 51,365, respectively, representing proportions of 10.1 and $5.7 \%$, respectively. In terms of the practical efficiency of foreign capital, the disparity between the eastern and western areas is obvious. The actual utilization of foreign capital in the eastern area reached US \$ 1,622.9 billion, accounting for $85.4 \%$ of the total investment. Guangdong and Jiangsu in the eastern area represent $40 \%$ of the total investment. The actual utilized foreign capital of these two provinces was much higher than the central region's US \$ 149,292 billion and the western region's US \$127,064 billion. To achieve harmonized and comprehensive progress, China has already implemented a plan to strengthen the midland and the large-scale development of the western region. However, due to the developed transportation and dense human resources in the eastern region, the gap between the eastern region and the central and western regions remains significant. However, with the enhancement of national preferential policies, the central and western regions are becoming increasingly attractive, and the practical efficiency of foreign funds is overall showing an increasing trend. This shows that the imbalance in the regional economic development level is an important reason for the imbalance in FDI distribution. GDP growth in the eastern region has had less impact on FDI inflows than that in the central region because the total amount of FDI used in the eastern region continues to accumulate; the law of diminishing marginal effects means that the impact of GDP growth on the promotion of FDI inflows is thus weakened.

Table 1

Absorption of foreign capital in China; regional distribution statistics

\begin{tabular}{|c|c|c|c|c|}
\hline Area & $\begin{array}{c}\text { Number of } \\
\text { businesses } \\
\text { (individuals) }\end{array}$ & $\begin{array}{c}\text { Proportion } \\
{[\%]}\end{array}$ & $\begin{array}{c}\text { Actual utilization } \\
\text { of foreign capital } \\
\text { [US \$ 100 million] }\end{array}$ & Proportion [\%] \\
\hline Eastern Region & 757828 & 84.2 & 16229.95 & 85.4 \\
\hline Central Region & 90763 & 10.1 & 1492.92 & 7.9 \\
\hline Western Region & 51365 & 5.7 & 1270.64 & 6.7 \\
\hline Total & 899956 & 100 & 18993.51 & 100 \\
\hline
\end{tabular}

(2) A comparison of FDI between in 2007 and 2016

FDI in China has experienced five development phases: in the initial stage from 1979 to 1991, China changed from excluding foreign capital to introducing foreign capital. To accommodate the constantly changing development environment and to meet the challenges of unpredictable changes, China's economy has changed from the pursuit of extensive quantitative expansion to the pursuit of quality and efficiency improvements and from the simple pursuit of economic growth to the improvement of economic efficiency. As shown in Figure 3, in 2007, the actual quantities of foreign capital used in China's primary, secondary and tertiary industries were US \$7,476,789 million, US \$ 4,286,106 million and US \$3,098,233 million, respectively. The practical amount of foreign funding used in primary industry was greater than the total amount of foreign funding used in secondary and tertiary industry combined. In 2016, the practical amount of foreign funding used in secondary industry was not much different, or even somewhat reduced, compared with that used in 2007. However, both primary industry and the service sector have witnessed 
substantial growth. The growth rate of foreign funding in primary industry is $68.52 \%$, while the growth ratio of foreign funding in tertiary industry is as high as $170.77 \%$, increasing from 30982.33 million US dollars in 2007 to 8380.987 million US dollars in 2016.

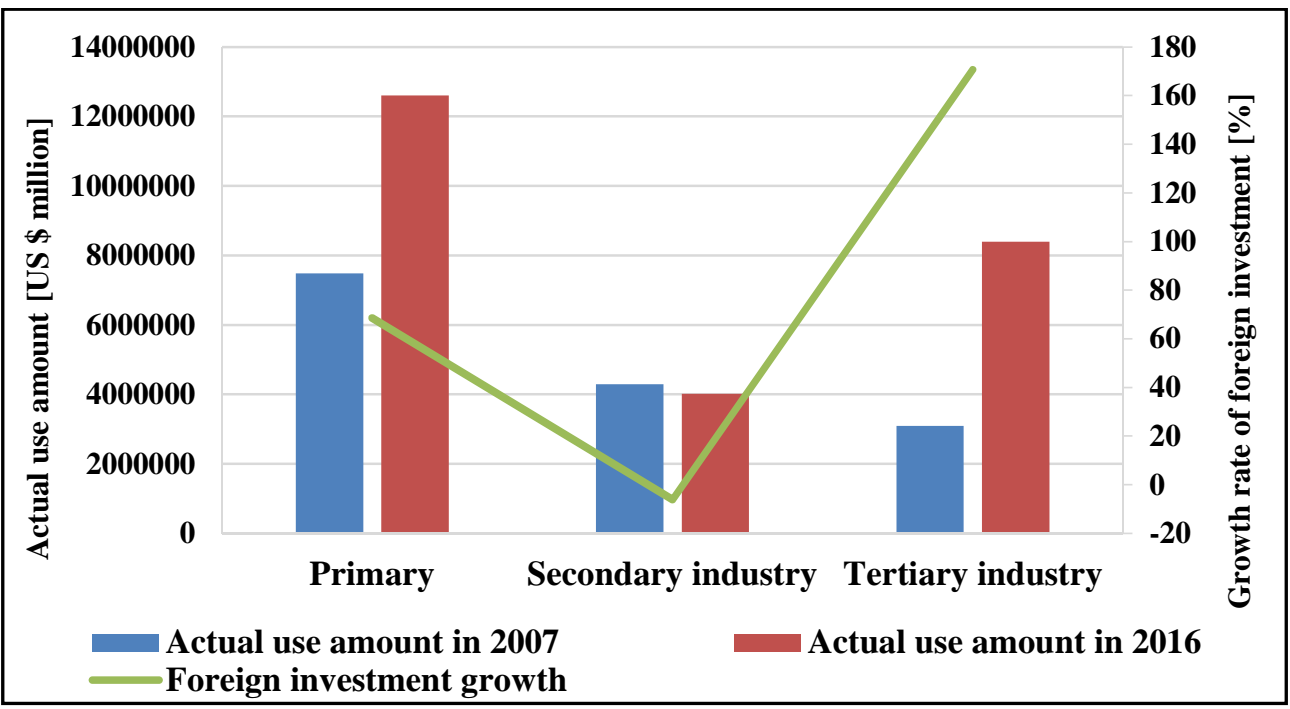

Fig. 3. Statistical chart of FDI in 2007-2016

\section{Overflow effects of FDI on environmental protection in China}

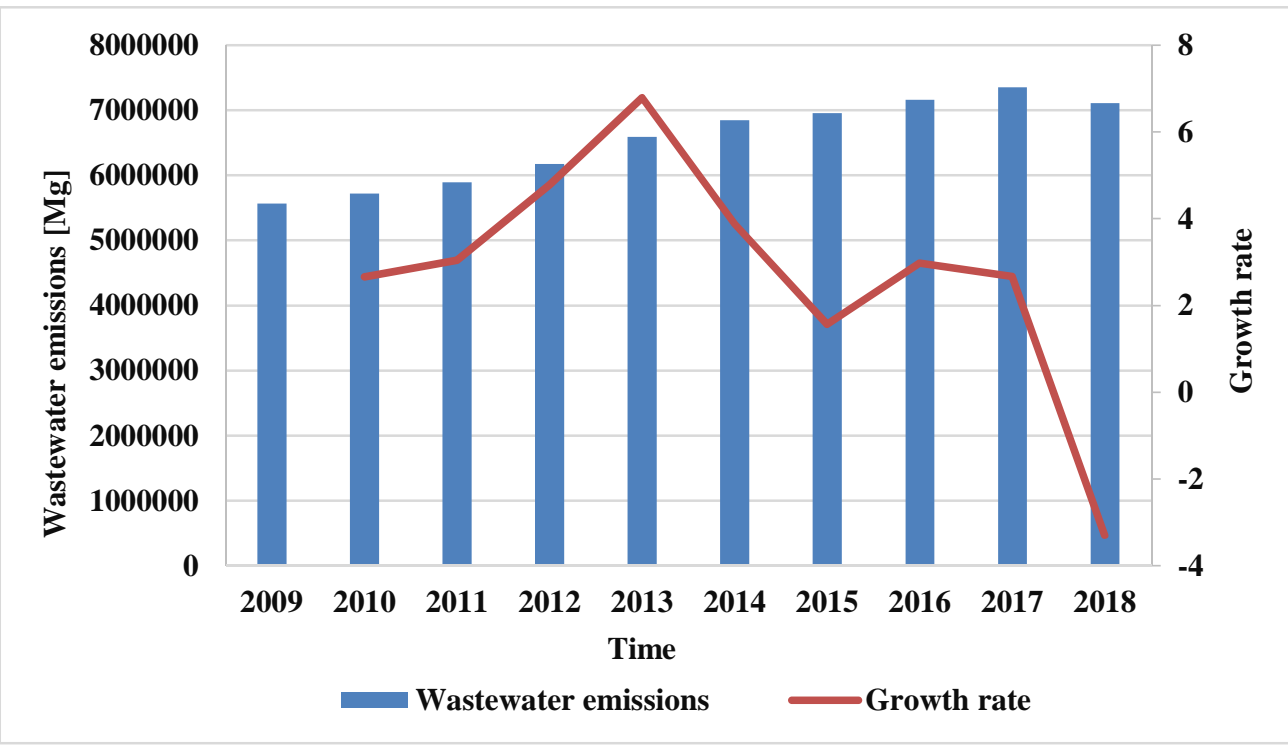

Fig. 4. Statistical chart showing total wastewater discharge from 2009 to 2018 
China's economy has been growing at a high speed, with an annual growth rate that has remained above $7 \%$. The country's overall strength has been enhanced, and people's living standards have been greatly improved. However, in the development process, China has been unilaterally chasing economic development, focusing on economic construction, and this has brought great damage to the environment. When China opened up to FDI, foreign investment mainly flowed into primary industry, and the most polluting area was manufacturing. In the manufacturing industry, polluting industries are prone to appear, which brings danger and damage to the environment. As shown in Figure 4, the growth rate of wastewater discharge began to decline after 2013, and in 2018, it decreased for the first time, with a growth rate of $-3.29 \%$. Therefore, while FDI promotes development, it also beyond doubt damages China's environment. However, any country will inevitably experience these effects in the early stage of national construction, so FDI has both positive and negative impacts on the surrounding environment. The unbalanced distribution of FDI can increase the unbalanced development of the regional economy; that is, the uneven distribution of FDI in China's three major regions widens their regional economic growth gap. In addition, the degree of export openness, human capital, and technological growth have a positive impact on GDP growth, although their degree of influence varies among regions.

\section{Conclusion}

Countries worldwide are becoming increasingly connected. No country or region can develop in isolation, without external cooperation. Every country or region should explore and study the overflow effect of FDI on sustainable development. Using the new political economy theory, this paper discusses the mechanism behind the overflow effect of FDI on China's sustainable development from this new perspective and deeply analyses its resulting influence on China's sustainable development. On this basis, combined with typical cases, suggestions are offered about the feasibility of FDI and the sustainable development of that have certain practical significance and reference value.

Global development has become increasingly complex and changeable, and this has increased the risk brought by FDI to China's sustainable development and brought new crises and challenges. However, China can give full play to the positive spillover effect of FDI and reduce its negative spillover effect as much as possible by relying on its unique institutional advantages to promote comprehensive sustainable development that allows economic gain, social development and environmental conservation. FDI plays an important role in China's development, both economic and social, and has made a certain contribution, and its active spillover effect is evident. However, with the continuous influx of FDI, negative spillover effects on China's sustainable development continue to emerge, especially for environmental protection. Therefore, China should reinforce its supervision of FDI, establish ideal laws and regulations, and establish a set of feasible and effective systems. First, China should grasp the relationship between the quantity and quality of FDI. With the continuous enhancement of China's endogenous capacity, some industries are growing and need to reduce or avoid FDI. Second, China should guide the direction of FDI. At present, the distribution of FDI in China is unbalanced, with more in the east and less in the west and more in primary industry and less in tertiary industry. To achieve coordinated and high-quality development, China needs to steer FDI to the western region and to the weak sectors of tertiary industry. Third, China should perfect its established laws and 
regulations and implement a set of feasible and effective systems. The legal system is a great hedge against risk. With regard to FDI, China should strengthen the construction of relevant legal systems, promote the reform of relevant systems, formulate relevant preferential policies according to the law and in light of the specific circumstances of China's development, and guide the development of FDI so that it can bring into full play the synergistic effect wherein one plus one becomes greater than two.

\section{Acknowledgements}

This work was supported by projects from the National Natural Science Foundation of China (41671118).

\section{References}

[1] Klugmann-Radziemska E, Rudnicka M. Energy yield generated by a small building integrated photovoltaic installation. Ecol Chem Eng S. 2020;27(3):335-46. DOI: 0.2478/eces-2020-0021.

[2] Lybecker KM. Innovation and technology dissemination in clean technology markets and the developing world: The role of trade, intellectual property rights, and uncertainty. Social Sci Electronic Publishing. 2015;10(1):7-38. DOI: 10.7341/20141021.

[3] Gilberthorpe E, Papyrakis E. The extractive industries and development: The resource curse at the micro, meso and macro levels. Extractive Industries Soc. 2015;2(2):381-90. DOI: 10.1016/j.exis.2015.02.008.

[4] Zang J, Wan L, Li Z, Wang C, Wang S. Does emission trading scheme have spillover effect on industrial structure upgrading? Evidence from the EU based on a PSM-DID approach. Environ Sci Pollut Res. 2020;27(1):12345-57. DOI: 10.1007/s11356-020-07818-0.

[5] Lu KL. The spillover effect of the trade war between adversarial dyads: Evidence from the Sino-US investment relationship. J Chinese Political Sci. 2020;25(1):21-47. DOI: 10.1007/s11366-018-9577-0.

[6] Men T. Place-based and place-bound realities: A Chinese firm's embeddedness in Tanzania. J Current Chinese Affairs - China Aktuell. 2014;43(1):103-38. DOI: 10.1177/186810261404300105.

[7] Hooda KS. Foreign investment in hospital sector in India. Foreign Trade Rev. 2017;52(4):247-64. DOI: $10.1177 / 0015732516681874$.

[8] Frasca CR. Foreign investment and environmental regulations in LDCs. Resource Energy Economics. 1999;21(21):191-9. DOI: 10.1016/S0928-7655(98)00032-3.

[9] Zilinske A. Incoming Foreign Investment: holly water or menu of potential troubles. Eng Economics. 2010;21(5):518-24. DOI: 10.1016/j.iref.2009.02.002.

[10] Al-Abri A, Baghestani H. Foreign investment and real exchange rate volatility in emerging Asian countries. J Asian Economics. 2015;37:34-47. DOI: 10.1016/j.asieco.2015.01.005.

[11] James RP. How U.S. firms evaluate foreign investment opportunities. Int Executive. 1972;14(1):9-11. DOI:10.1002/tie.5060140106.

[12] Richardson DJ. On "going abroad": The firm's initial foreign investment decision. Thunderbird Int Business Rev. 2015;14(3):15. DOI: 10.1002/tie.5060140309.

[13] Huang SP, Ma SZ, Pan Y, Li Y, Tsai SB. An empirical study on how climate and environmental issues awareness affects low carbon use behaviour. Ecol Chem Eng S. 2020;27(1):55-66. DOI: 10.2478/eces-2020-0003.

[14] Anwar S, Sun S. Can the presence of foreign investment affect the capital structure of domestic firms? J Corporate Finance. 2015;30:32-43. DOI: 10.1016/j.jcorpfin.2014.11.003.

[15] Eduardo AG, Malan PS, José Tavares de Araujo Jr. Changing international investment strategies: The "New Forms" of foreign investment in Brazil. Embo J. 2015;6(9):866-72. DOI: 10.1038/sj.embor.7400483.

[16] Sornarajah M. The precursor of neoliberalism: internationalization of foreign investment contracts. Chapter 2. In: Resistance and Change in the International Law on Foreign Investment. Cambridge University Press; 2015:78-135. DOI: 10.1017/CBO9781316156339.003.

[17] Chen Y, Zheng W, Li W, Huang W. The robustness and sustainability of port logistics systems for emergency supplies from overseas. J Advanced Transportation. 2020;(1):1-10. DOI: 10.1155/2020/8868533.

[18] Lv Z, Li X, Li W. Virtual reality geographical interactive scene semantics research for immersive geography learning. Neurocomputing. 2017;254:71-8. DOI :10.1016/j.neucom.2016.07.078. 